\title{
Vorwort zur Neuen Folge der nachgelassenen Werke
}

Hans Joachim Iwand ist einer der bedeutendsten evangelischen Theologen des 20. Jahrhunderts. Zur Veröffentlichung seiner Arbeiten ist er selbst kaum gekommen. Erst nach seinem Tod haben einige seiner Freunde "Nachgelassene Werke" herausgegeben, die in sechs Bänden im Zeitraum zwischen 1962 und 1974 erschienen. Zwischen 1959 und 1980 kamen zwei Bände "Gesammelte Aufsätze» heraus, 1988 ein Band politisch-theologischer Beiträge. Wir freuen uns, diese Folge mit einem Band „Predigten und Predigtlehre" abschließen zu können.

Leider müssen wir der Leserschaft mitteilen, dass der geplante Band mit Briefen Iwands nicht erscheinen wird. Wie schon bei der Planung der ersten Reihe nachgelassener Werke ergaben sich für die Veröffentlichung einer Auswahl von Briefen - um mehr hätte es sich ohnehin nicht gehandelt - unüberwindliche Schwierigkeiten.

Wir danken nach mehreren Seiten: denen, die mit finanziellen Zuschüssen diese Edition ermöglicht haben, der St. Marien-Gemeinde in Dortmund, der Evangelischen Kirche in Hessen und Nassau, der Evangelischen Kirche im Rheinland und der Evangelischen Landeskirche in Württemberg; den Erben Iwands für die Zustimmung zur Veröffentlichung; den Bearbeitern der Bände; sowie dem Verlag, besonders den Herren Hansjürgen Meurer und Diedrich Steen.

Der Vorstand der Hans-Iwand-Stiftung 
